\title{
Blocking Nogo Receptor 1 Promotes Functional Regeneration after Spinal Cord Injury
}

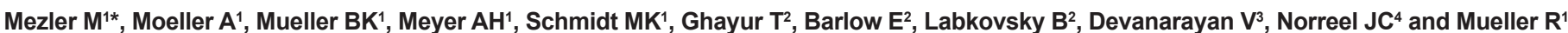

${ }^{1}$ Neuroscience Research, Global Pharmaceutical Research \& Development, AbbVie, 67061 Ludwigshafen, Germany

${ }^{2}$ AbbVie Bioresearch Center, 100 Research Drive, Worcester MA 01605, USA

${ }^{3}$ Exploratory Statistics, AbbVie, Souderton, PA 18964, USA

${ }^{4}$ Pharmaxon, IBDM, Parc Scientifique de Luminy, Case 907, 13288 Marseille Cedex 09, France; current address : KIS Healthcare Ltd. PMI PIc., Church Road, Bookham,

Surrey KT23 3EU, UK

\begin{abstract}
An insult to the mammalian spinal cord often results in persistent functional deficits. Proteins in CNS myelin are important determinants of this situation as they inhibit neurite growth. Among those proteins Nogo-A, oligodendrocyte myelin glycoprotein (OMgp), and myelin-associated glycoprotein (MAG) all bind to the neuronal Nogo-66 receptor (NgR1) and thereby block neuronal regeneration after injury. Neutralizing the interaction between the inhibitory ligands and NgR1 may alleviate the inhibition and therefore result in increased recovery after injury. Thus, antibodies neutralizing ligand/receptor interaction might have therapeutic value.

From a set of 300 monoclonal anti-NgR1 antibodies one anti-NgR1 ligand blocking antibody (mAb50) was selected for in vivo studies. mAb50 binds with high affinity (below $100 \mathrm{pM}$ ) to human and rat NgR1, competes for binding of a ligand peptide (derived from Nogo-A: Nogo66) to the isolated NgR1 protein and cellular NgR1, and reduces the inhibitory effects of Nogo66 on neurite outgrowth in differentiated human NTera2 cells and rat dorsal root ganglion neurons. In a rat spinal cord hemisection model mAb50 enhanced functional locomotor recovery. These data suggest that neutralization of $\mathrm{NgR} 1$ activity with an antibody may be a valuable strategy to neutralize neurite outgrowth inhibition in the mammalian CNS. Thus anti-NgR1 antibodies are a potential approach for the treatment of spinal cord injury and even neurodegenerative diseases.
\end{abstract}

Keywords: Nogo-66 receptor; Myelin; Neurite outgrowth inhibition; Spinal cord injury; Regeneration after injury; Rat

Abbreviations: BBB: Basso Beatty Bresnahan; CGN: Cerebellar Granule Neuron; CHO: Chinese Hamster Ovary; CSN: Central Nervous System; CSPG: Chondroitin Sulfate Proteoglycan; CST: Corticospinal Tract; DRG: Dorsal Root Ganglion; ELISA: Enzymelinked Immunosorbent Assay; FACS: Fluorescence Activated Cell Sorting; GPI: Glycophosphatidylinositol; HEK: Human Embryonic Kidney; LILRB2: Leukocyte Immunoglobulin (Ig)-like Receptor; Mab: Monoclonal Antibody; MAG: Myelin-Associated Glycoprotein; MAI: Myelin-Associated Inhibitor; NgR1: Nogo-66 Receptor; OMGP: Oligodendrocyte Myelin Glycoprotein; PirB: Paired Immunoglobulinlike Receptor B; RU: Resonance Unit; SCI: Spinal Cord Injury

\section{Introduction}

In the adult mammalian central nervous system (CNS) the capability of repair after injury is limited. In the case of spinal cord injury, this often leads to deficits caudal to the lesion site, causing everlasting paralysis, insensitivity and lack of vegetative functions [1].

Intensive research efforts have sought to identify the cause of this lack of regenerative capabilities in adult CNS. It is now accepted that injured nerve fibers in the CNS are intrinsically capable to regrow [2]. However, inhibitory factors within the CNS actively prevent regrowth, and thus inhibit regeneration of the injured fiber tracts. Especially CNS myelin is an important non-permissive factor causing growth cone collapse in vitro as well as in vivo, which results in the direct inhibition of axon outgrowth [3]. Among major inhibitory proteins within CNS myelin, oligodendrocyte myelin glycoprotein (OMgp), Myelin associated glycoprotein (MAG) and Nogo-A [4-7] interact with the same receptor, the Nogo-66 receptor (NgR1) [8]. NgR1 is a GPI-anchored protein expressed in neurons of the adult CNS $[9,10]$. NgR1 and its analogue NgR3 are receptors for chondroitin sulfate proteogylcans (CSPGs)
[11] also, and $\mathrm{NgR} 1$ has been demonstrated to interact with additional functional proteins, including olfactomedin 1 [12] and leucine-rich glioma inactivated (LGI1) [13]. For signal transduction NgR1 interacts with co-receptors p75 or TROY, and Lingo-1 [14-17]. In spite of this high complexity and the apparent redundancy of the inhibitory systems in the CNS, interfering with the NgR1 system through an antagonist peptide NEP1-40 $[18,19]$ or a soluble NgR1 protein [20] resulted in increased sprouting of axonal fibers of the corticospinal tract (CST) in rodents with experimental spinal cord injury. Furthermore, improved functional recovery after spinal cord injury; for example as measured through the Basso, Beattie, Bresnahan locomotor rating scale [21] was described in these publications. The effects of genetic ablation of NgR1 are controversial. While no differences in corticospinal tract (CST) regeneration were observed between $\mathrm{NgR} 1(-/+)$ mice and wild type mice by two groups $[22,23]$, one of those found significantly better functional regeneration in $\mathrm{NgR} 1(-/-)$ mice compared to controls [22]. Additional studies questioned the importance of $\mathrm{NgR1}$ in chronic growth inhibition mediated by myelin ligands [24] and confirmed only partially the regeneration promoting action of NEP1-40 [25]. All three NgR1 ligands bind to a second receptor, PirB, which is also implicated in neuronal regeneration [26]. These results further add to the complexity of neurite outgrowth inhibition in the CNS.

*Corresponding author: Mario Mezler, AbbVie Deutschland $\mathrm{GmbH}$ \& Co. KG, Neuroscience Discovery, Department of Biology, Knollstrasse 50, 67061 Ludwigshafen, Germany; Tel: (49) 621589 4602; Fax: (49) 621589 3232; E-mail: mario.mezler@abbvie.com

Received June 18, 2013; Accepted August 12, 2013; Published August 15, 2013

Citation: Mezler M, Moeller A, Mueller BK, Meyer AH, Schmidt MK, et al. (2013) Blocking Nogo Receptor 1 Promotes Functional Regeneration after Spinal Cord Injury. J Neurol Disord 1: 128. doi:10.4172/2329-6895.1000128

Copyright: ๑ 2013 Mezler M, et al. This is an open-access article distributed under the terms of the Creative Commons Attribution License, which permits unrestricted use, distribution, and reproduction in any medium, provided the original author and source are credited. 
To elucidate the role of $\mathrm{NgR1}$ in neurite outgrowth further, we decided to target the receptor and developed highly potent, neutralizing anti-NgR1 antibodies. We compared their properties with the described selective anti-NgR1 antibody 7E11 [27]. Our results support a central role of $\mathrm{NgR} 1$ in neurite outgrowth inhibition in adult CNS, but also indicate that additional inhibitory systems are also involved in the control of regeneration of CNS function after injury.

\section{Materials and Methods}

\section{Recombinant proteins}

Generation of human and rat NgR1: A cDNA encoding amino acids 27-450 of the human NgR1 (accession number AAG53612) with carboxyterminal myc and hexa-His tags (hNgR1-His) was cloned into a pSec vector (Ambion; Life Technologies, Darmstadt, Germany). The protein was generated by stable expression in $\mathrm{CHO}-\mathrm{K} 1$ cells cultivated in UltraCHO serum-free medium (Cambrex Bio Science, Rockland Inc., Rockland, USA). The conditioned medium was centrifuged and concentrated with Hemoflow F columns (Fresenius Medical Care, Bad Homburg, Germany). hNgR1-His protein was then purified with Ni-NTA-Superflow (Qiagen, Hilden, Germany), dialyzed overnight $\left(6^{\circ} \mathrm{C} ; 25 \mathrm{mM}\right.$ Tris/ $\left.\mathrm{HCl}, \mathrm{pH} 7.0\right)$ and further purified on a Q-Sepharose column (Amersham, GE Healthcare, Freiburg, Germany). Finally, the protein solution was again dialyzed and passed through a $0.2 \mu \mathrm{m}$ sterile filter. For long time storage the proteins were aliquoted and stored at $-80^{\circ} \mathrm{C}$.

The rat NgR1 DNA (accession number AAM46772), encoding amino acids 27 through 450 carboxy-terminally coupled to a $6 \mathrm{x}$ His tag (rNgR1-His) was cloned into pcDNA3.1 (Invitrogen). The protein was generated in a transient expression system in HEK293F cells under standard conditions and the conditioned medium harvested after 4872 hours. Purification of the protein was essentially as described above for the human protein. In some experiments, commercially available human recombinant $\mathrm{NgR} 1 / \mathrm{Fc}$ chimera and recombinant mouse Nogo receptor/Fc chimera proteins were used (R\&D Systems, Wiesbaden, Germany; \#1208-NG, \#1440-NG).

Generation of alkaline-phosphatase coupled Nogo66 (APNogo66): Briefly, Nogo66 was cloned into the pAPTag5 vector, and stably expressed in HEK293 cells. For protein production AP-Nogo66 expressing cells were cultivated in RPMI medium (Invitrogen) containing 10\% FCS until confluence. Medium was exchanged to Pro293a-CDM (Cambrex Bio Science) and cells cultivated for 3 days. After addition of $1 \mathrm{mM}$ PefablocSC (Roche, Mannheim, Germany) the conditioned medium was concentrated with Hemoflow F columns (Fresenius Medical Care). AP-Nogo66 content in the supernatant was determined by measuring AP enzyme activity using AttoPhos substrate (Roche) and a Polarstar plate reader (BMG Labtech, Ortenberg, Germany). The AP-Nogo66 concentrate was aliquoted and frozen at $-80^{\circ} \mathrm{C}$.

Cell surface expression of NgR1: The full-length receptor (rat AAM46772 and human AAG53612) was cloned into pcDNA4. Stable CHO-K1 and HEK293 cells were generated under standard procedures and protein expression verified by FACS. For transient expression in HEK293F, cells were transfected in suspension according to the manufacturer (Freestyle System (Invitrogen)), harvested after $48 \mathrm{~h}$ and used for FACS studies.

\section{Production of antibodies and antibody generating cell lines}

Generation of hybridoma cells: A/J mice (The Jackson Laboratories, Bar Harbor, Me, USA) were immunized with recombinant human or rat (generation of mAb50) $\mathrm{NgR} 1$ protein (NgR1-His) in Complete Freund's adjuvant for the first injection and Immuneasy (Qiagen) for the last three immunizations. Four days prior to fusion, mice were injected with $10 \mu \mathrm{g}$ of antigen intravenously. For the fusion, spleen cells from immunized animals were fused with SP2/0-Ag14 myeloma cells at a ratio of 5:1 using standard techniques [28]. Seven to ten days post fusion, when macroscopic hybridoma colonies were observed; supernatants were tested by ELISA assays. Hybridoma cells producing antibody-positive in the ELISA-were scaled up and subcloned by limited dilution cloning. Antibodies that reacted in the ELISA assays were then tested for binding to HEK293 or CHO cells stably expressing recombinant human or rat $\mathrm{NgR} 1$, and not to their non-transfected or control cells. The isotype of the antibody was determined using the Zymed EIA isotyping kit (Zymed Laboratories Inc, Invitrogen, San Francisco, USA).

Affinity determination with Biacore: $\mathrm{mAb} 50$ was captured using a Goat Anti mu IgG-Fc surface (5000 resonance units (Ru)); antibodies were captured at 100-200 Rus for measurement in a Biacore (GE Healthcare). Both antigens (either human or rat NgR1) were injected at a concentration range of 1.25 to $100 \mathrm{nM}$. The surface was regenerated using $10 \mathrm{mM}$ glycine $\mathrm{pH} 1.5$. Flow rate was $50 \mu \mathrm{l} / \mathrm{min}$.

Generation of the anti-NgR1 antibody 7E11: The variable domains of the heavy and light chains of antibody 7E11 were assembled according to published sequences [27] by PCR extension of overlapping oligonucleotides, and then cloned into murine IgG1 Kappa expression cassette vectors. Transfections of HEK293 cells were performed with these expression plasmids, and the secreted antibody was purified from cell culture supernatants by Protein-A chromatography.

Sequencing of mAb50, ATCC deposit: RNA from approximately one million hybridoma cells from clone 50 was prepared using Qiagen RNAeasy kit. The Qiagen One Step RT-PCR kit was used to make cDNA, and fragments containing the heavy $(\mathrm{VH})$ and light $(\mathrm{VL})$ chain variable regions were generated using the Novagen mouse IgG primer set (Merck Millipore, Nottingham, UK). The isolated VH and VL domains were cloned into pCR2.1-TOPO vector (Invitrogen), and a consensus sequence for each chain was gained by sequencing multiple clones with M13 primers. Hybridoma 50 was deposited with ATCC under the Budapest Treaty, deposit number PTA-8383.

Protein-based binding assays: Different plate assay formats were established and used to identify antibodies that bind to the human, rat or mouse $\mathrm{NgR} 1$ and compete for $\mathrm{NgR} 1 /$ ligand interactions. For receptor binding studies, NgR1 proteins (human and mouse NgR1-Fc from R\&D Systems; rat NgR1) were immobilized at $0.2 \mu \mathrm{g} /$ well on 96 well microtiter plates over night (Nunc Maxisorp; Thermo Scientific, Langenselbold, Germany), nonspecific binding sites were blocked with $2 \%$ bovine serum albumin (BSA) in Tris- $\mathrm{HCl}, \mathrm{pH} 7.2$ for $2 \mathrm{~h}$ at room temperature, plates incubated with anti-NgR1 antibodies, washed and bound antibody detected with a secondary anti-mouse antibody labeled with horseradish peroxidase (Sigma Aldrich, Seelze, Germany) and developed using 3,3',5,5'-tetramethylbenzidine substrate (TMB; Pierce, Thermo Scientific) under standard conditions.

In the AP-Nogo66 competition assay human NgR1-Fc $(0.2 \mu \mathrm{g}$ per well) was immobilized on 96-well microtiter plates (Nunc Maxisorp; Thermo Scientific) in $50 \mathrm{mM} \mathrm{NaHCO}_{3}$ buffer, $\mathrm{pH}$ 9, over night at $4^{\circ} \mathrm{C}$, followed by a $2 \mathrm{~h}$ blocking step with $2 \% \mathrm{BSA}$ in Tris- $\mathrm{HCl}, \mathrm{pH} 7.2$ at room temperature. The wells received a constant concentration of 0.15 nM AP-Nogo66 in Tris-HCl, pH 7.2 with $0.1 \%$ BSA and increasing concentrations of the antibodies. During each incubation step, plates were washed with washing buffer $(10 \mathrm{mM}$ Tris- $\mathrm{HCl}, \mathrm{pH} 7.2$ with $0.05 \%$ 
Tween20). Binding of AP-Nogo66 was detected with the AttoPhos substrate (Roche) and the fluorescence units were measured in the Polarstar instrument (BMG).

For MAG-Fc binding, MAG-Fc (R\&D Systems) was labeled with horseradish peroxidase employing the Zenon human IgG labeling kit (Molecular Probes, Life Technologies) to generate peroxidase-coupled MAG-Fc (POD-MAG-Fc). Wells containing immobilized NgR1$\mathrm{Fc}$ received a constant concentration of POD-MAG-Fc $(0.42 \mathrm{nM}$ in Tris- $\mathrm{HCl}, \mathrm{pH} 7.2$ with $0.1 \% \mathrm{BSA}$ ) and the indicated concentrations of antibodies. After each incubation step plates were washed with washing buffer (10 mM Tris-HCl, pH 7.2 with $0.05 \%$ Tween 20 ). Bound PODMAG-Fc was detected using 3,3',5,5'-tetramethylbenzidine substrate (TMB; Pierce, Thermo Scientific) under standard conditions.

For OMgp binding, ELISA plates (Nunc Maxisorp; Thermo Scientific) were coated with $50 \mathrm{ng} \mathrm{NgR1-Fc} \mathrm{per} \mathrm{well} \mathrm{in} 50 \mathrm{mM} \mathrm{NaHCO}_{3}$ buffer, $\mathrm{pH} 9.0$, over night at $4^{\circ} \mathrm{C}$ (1208-NG; R\&D Systems). Plates were blocked for $1 \mathrm{~h}$ with buffer (20 mM Tris- $\mathrm{HCl}$ with $2 \% \mathrm{BSA}, \mathrm{pH} 7.4)$, washed three times with washing buffer $(20 \mathrm{mM}$ Tris- $\mathrm{HCl}$ with $0.05 \%$ Tween) and $0.2 \mu \mathrm{M}$ OMgp (R\&D Systems) with or without competitors in $20 \mathrm{mM}$ Tris- $\mathrm{HCl}$ with $0.1 \% \mathrm{BSA}, \mathrm{pH} 7.4$ was added and incubated for $2 \mathrm{~h}$. After 3 washing steps ( $20 \mathrm{mM}$ Tris- $\mathrm{HCl}$ with $0.05 \%$ Tween), anti-His6-Peroxidase was added and incubated for $1 \mathrm{~h}$. 3 washes with washing buffer were followed by 2 washes with $20 \mathrm{mM}$ Tris- $\mathrm{HCl}, \mathrm{pH}$ 7.4 and TMB substrate was added (Pierce, Thermo Scientific). The developing reaction was stopped after 15 min with $2 \mathrm{M} \mathrm{H}_{2} \mathrm{SO}_{4}$ and the absorption measured at $450 \mathrm{nM}$.

\section{FACS analysis}

HEK293F cells transiently expressing human or rat $\mathrm{NgR} 1$ as well as HEK293 and CHO-K1 cells stably expressing the receptor, and natively expressing cells were employed. For competition of AP-Nogo66 binding by antibodies, cells were suspended in PBS with $1 \%$ BSA, $40 \mathrm{nM}$ of APNogo66 and varying concentrations of monoclonal antibodies $(5.3,27$, 133 , and $670 \mathrm{nM}$ ) for $1 \mathrm{~h}$ at $4^{\circ} \mathrm{C}$. A monoclonal antibody of the same isotype as the anti-NgR1 antibodies (IgG2a/k) was used as a negative control. The binding of AP-Nogo66 was detected with an anti-alkaline phosphatase antibody (Sigma), which was labeled with Alexa Fluor using the Zenon mouse IgG2a labeling kit (Invitrogen). This secondary antibody was incubated for $1 \mathrm{~h}$ at $4^{\circ} \mathrm{C}$. At the end of the incubation, the cells were washed with PBS and subjected to FACS analysis.

\section{Neurite outgrowth in human NTera2 cells and rat dorsal root ganglion neurons}

NTera2 (human embryonal carcinoma (EC) stem cells; German National Resource Center for Biologicals, DMSZ, Braunschweig, Germany) were thawed and plated in $175 \mathrm{~cm}^{2}$ culture flasks (Greiner bio-one) with DMEM medium (Gibco), containing 10\% fetal calf serum (FCS) and 5\% Horse Serum, as described before [29]. For differentiation, retinoic acid (SIGMA) at a final concentration of 10 $\mu \mathrm{M}$ was added twice-weekly to the NTera 2 cells over a period of three weeks. Subsequently, the cells were replated.

After 2-3 days cells were dislodged by gentle tapping, and cells $\left(10^{6}\right.$ cells $\left./ \mathrm{ml}\right)$ were added to aggregation medium (Neurobasalmedium (Gibco, Invitrogen) containing $2 \mathrm{mM}$ L-Glutamine (Gibco, Invitrogen) with Penicillin/Streptomycin and B27-Supplement), gently agitated over night at $37^{\circ} \mathrm{C}, 5 \% \mathrm{CO}_{2}$ and plated on 96 well plates (Biocoat Poly-D-Lysin Cellware 96-Well Black/Clear Plate (Becton Dickinson, Heidelberg, Germany)), pre-coated with inhibitory or control substrates. For the inhibitory substrates the wells were coated with
$15 \mu \mathrm{g} / \mathrm{ml}$ AP-Nogo66 plus $1 \mathrm{mg} / \mathrm{ml}$ laminin (Sigma) in sterile PBS (20 $\mu \mathrm{g}$ laminin per well). For the permissive substrate the wells were coated with $20 \mu \mathrm{g}$ laminin. After an incubation of $2 \mathrm{~h}$ the plates were washed twice with PBS and $50 \mu \mathrm{l}$ of the pre-aggregated cell suspension was plated in each well, supplemented with $40 \mu \mathrm{l}$ of medium. Plates were incubated at $37^{\circ} \mathrm{C}$ for 2 hours, and finally $10 \mu \mathrm{l}$ of pre-diluted antibody solution was added to give a final antibody concentration between 1 and $100 \mu \mathrm{g} / \mathrm{ml}$. Cells were incubated over night at $37^{\circ} \mathrm{C}, 5 \%$ $\mathrm{CO}_{2}$, the following day fixed with $2 \%$ paraformaldehyde (Sigma) and stored at $4^{\circ} \mathrm{C}$ for subsequent analysis. Fixed cultures were stained with Alexa-phalloidin and analysis of neurite outgrowth was performed automatically with the software AxioVision LE Rel. 4.1 (Carl Zeiss, Jena, Germany), according to a published protocol [29]. Data were analyzed by ANOVA followed by Bonferroni's test using GraphPad Prism software (Graph Pad Software, La Jolla, USA). Values $\mathrm{p}<0.05$ was regarded as statistically significant.

For the preparation of dorsal root ganglion (DRG) neurons, P4-6 (postnatal day 4-6) rat pups were decapitated with a surgical scissor. The vertebral column was dissected free and opened longitudinally. The spinal cords were removed together with the adhering DRGs and were transferred to a petri dish containing PBS. DRGs were isolated and collected in $1 \mathrm{ml}$ PBS. $0.5 \mathrm{ml}$ of collagenase solution $(4 \mathrm{mg} / \mathrm{ml}$ collagenase Type I in PBS; Worthington Biochemical Corporation, Lakewood, USA) was added and the DRGs were incubated for 20-30 min at $37^{\circ} \mathrm{C}$. $0.5 \mathrm{ml}$ of trypsin solution $(0.5 \%$ trypsin in PBS (SERVA Feinbiochemica GmbH \& Co., Heidelberg, Germany)) was added and the DRGs were incubated for further $15-25 \mathrm{~min}$ at $37^{\circ} \mathrm{C}$. The DRGs were transferred into medium (DMEM Nut Mix F12 (Gibco), 5\% heat inactivated FBS (Gibco); 5\% heat inactivated horse serum (Sigma), 1\% penicillin/streptomycine (Gibco)). After settlement of the DRGs the supernatant was removed. DRGs were dissociated in medium by 3-5 passages through a Pasteur pipette, followed by 2-3 additional passages through a Pasteur pipette with a reduced opening. After settling of cell clumps, dissociated cells were collected by centrifugation for $5 \mathrm{~min}$ at $1000 \mathrm{rpm}$, resuspended in medium, counted, and diluted to the desired cell density in medium supplemented with Nerve Growth factor (NGF; $62.5 \mu \mathrm{g} / \mathrm{ml}$ final concentrations, Roche). 4000-7000 cells were placed in a poly-lysine coated 96 well plate (Becton Dickinson), additionally coated with laminin (Sigma; $20 \mu \mathrm{g} / \mathrm{ml}$ in water), and incubated at $37^{\circ} \mathrm{C}$ between $30 \mathrm{~min}$ and $3 \mathrm{~h}$.

For testing, antibodies were added and the cell culture incubated for $2 \mathrm{~h}$ in a $\mathrm{CO}_{2}$ incubator at $37^{\circ} \mathrm{C}$. Subsequently, AP-Nogo66 at a final concentration of 7.3 nM was added. Cells were grown for 18-30 $\mathrm{h}$ and fixed with $4 \%$ paraformaldehyde solution in PBS (phosphatebuffered saline; Gibco) at $4^{\circ} \mathrm{C}$ for at least $12 \mathrm{~h}$. Neurite outgrowth was visualized by indirect immunofluorescence using an anti-ßIII tubulin antibody (ab14545; Abcam) in conjunction with a Cy3conjugated secondary antibody (Jackson ImmunoResearch, Dianova, Hamburg, Germany). Nuclei were stained by addition of Bisbenzimide (H33258). Microscopic pictures were taken on a BDTM Pathway Bioimager (Becton Dickinson) at 10x magnification and neurite length was determined using the AttoNO (Becton Dickinson) software (1 pixel $=1.25 \mu \mathrm{m}$ ). Data were analyzed by ANOVA followed by Dunnett's test using GraphPad Prism (GraphPad Software). Values $\mathrm{p}<0.05$ was regarded as statistically significant.

\section{Spinal cord over-hemisection}

mAb50 was chosen for spinal cord injury studies. The antibody was tested for stability in a buffer containing $10 \mathrm{mM}$ citric acid, $10 \mathrm{mM}$ phosphoric acid, $0.3 \%$ sodium chloride and $5 \%$ sucrose at $\mathrm{pH} 6$. The 
antibody was soluble and stable in this buffer for over 26 days at $40^{\circ} \mathrm{C}$ up to a concentration of $50 \mathrm{mg} / \mathrm{ml}$. For the over-hemisection study, female Wistar rats (230 g; Janvier, Orleans, France) were housed in individual cages with free access to food and water in a 12:12 hour light/dark cycle. For surgery, the rats were anesthetized $(80 \mathrm{mg} / \mathrm{kg}$ ketamine, $10 \mathrm{mg} /$ $\mathrm{kg}$ xylazine IP). Ophtalmic ointment (Ducray, Castres, France) was applied on both eyes to avoid corneal desiccation. Rats were randomly assigned to 1 of the 3 experimental groups $(25 \mathrm{mg} / \mathrm{ml} \mathrm{mAb50;5} \mathrm{mg/}$

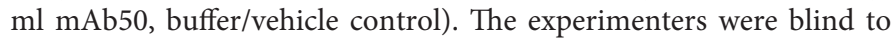
the identity of the reagents. After performing a laminectomy at T8 and $\mathrm{T} 9$ the spinal cord was exposed over $2-2.5 \mathrm{~mm}$. Using iridectomy scissors, a dorsal over-hemisection (ca. 60\%) was performed at 1.8 $\mathrm{mm}$ depth, followed by a cut with a fine scalpel to ensure complete lesion. At T12-T13 a second partial laminectomy was performed. An Alzet (Cupertino, CA, USA) polyurethane Teflon coated catheter was inserted from T12-T13 in the central canal and intrathecally inserted and advanced until the tip of the catheter reached the lesion site. The catheter was attached to an osmotic minipump (Alzet model 2002, Alzet Osmotic Pumps, Durect Corporation, Cupertino, CA, USA), which had previously been filled with a small syringe $(1.0 \mathrm{ml})$ using a blunt tipped 27 gauge filling needle. Each pump was submersed in sterile saline at $37^{\circ} \mathrm{C}$ for at least $4-6$ hours before implantation to ensure the starting of the flow and immediate release of the test compound. Prior to implantation the catheter was also filled with the appropriate solution and fixed to the pump immediately before surgery. At P35, the rats were anesthetized as previously described. The corticospinal tract (CST) was selectively labeled by injecting fluororuby into the primary motor cortex area (M1). To this aim, six microliters of a $10 \%$ fluororuby solution were unilaterally injected using an electrical syringe at 3 different points in order to fully label the M1 region (bregma: ant .-0.5; -1.75; $-3 \mathrm{~mm}$; lat: $+2 \mathrm{~mm}$; deep: $+2 \mathrm{~mm}$ ). The scalp was then closed using cutaneous thread. At P42, rats were anaesthetized with a mixture of $120 \mathrm{mg} / \mathrm{kg}$ ketamine and $14 \mathrm{mg} / \mathrm{kg}$ xylazine, transcardially perfused with $\mathrm{Ca}^{2+}-$ \& $\mathrm{Mg}^{2+}$-free Dulbecco's phosphate buffered saline (PBS; Eurobio, Courtaboeuf, France), followed by $4 \%$ paraformaldehyde (PFA; SIGMA-ALDRICH) in PBS. Perfusion rate was set at $34-40 \mathrm{ml} /$ min in order to avoid fixation artifacts. Spinal cords were immediately dissected and postfixed for $2 \mathrm{~h}$ at $4^{\circ} \mathrm{C}$ in fixative. Following postfixation, tissue samples were washed in PBS and cryoprotected for 3 days at $4^{\circ} \mathrm{C}$ in $\mathrm{PBS} / 30 \%$ sucrose. Lesion depth and outgrowth of the corticospinal tract were measured in longitudinal sections of the spinal cord. Incision depth in the spinal cord was controlled at the end of the study and was determined to be $57.5 \%$ in average.

\section{Analysis of the behavioral recovery (BBB)}

Motor recovery was assessed for 6 weeks after injury in an open field environment by means of the Basso-Beattie-Bresnahan (BBB) locomotor rating scale [21]. BBB scores were assigned by 2 experimenters, blinded for the different groups by observing each rat for 4 min behaving in a standardized open-field. Before surgery at post-operative day $0(\mathrm{P} 0)$, the rats were left for $4 \mathrm{~min}$ in the open field in order to let them discover the arena and ensure that they were behaving normally. BBB scores were analyzed at post-operative day 1 (P1), P4, P7, P14, P21, P28, P35 and P42. The left and right hindlimbs were graded separately and then averaged. To ensure that the potential inter-animal surgery variability had low effects on the motor scores, $\mathrm{BBB}$ scores were also retreated using a motor criterion. Rats with $\mathrm{BBB}$ $>5$ at $\mathrm{P} 4$ and with $\mathrm{BBB}<5$ at $\mathrm{P} 14$ were considered as incompletely or too deeply transected, respectively [30]. Furthermore, animals with self-injury at the limbs and trunk were excluded from further studies and euthanized. Final cohort size at the end of the experiment was 13 (25 mg/ml mAb50), 14 (5 mg/ml mAb50) and 16 (vehicle control).

The retreated $\mathrm{BBB}$ scores were then compared between the vehicle and each of the dose groups within the framework of a mixed effects (repeated measures) model. In this model, treatment group (vehicle and two dose groups), day (P1, P4, P7, P14, P21, P28, P35 and P42), and group ${ }^{*}$ day interaction were included as fixed effects, and animal nested within group was included as random effect. From this model, the treatment groups were compared by averaging across all days (using the group main effect), and also compared for each day (using the group ${ }^{\star}$ day interaction).

Similar analyses on the retreated BBB data were performed by combining the days into two time periods: P1-P7 and P14-P42. Therefore in the above mixed effects model, the individual days were replaced by these two time periods. Within the framework of this model, the treatment groups were compared separately for these two time periods. i.e., vehicle versus each of the two dose groups during days P1-P7 and days P14-P42.

\section{Cerebrospinal fluid collection and antibody measurements}

CSF samples were obtained from cisterna magna punctures and the concentration of mAb50 was measured with a sandwich enzymelinked immunosorbent assay.

\section{Animal care}

For the spinal cord over-hemisection model, protocols were submitted to and approved by the National Scientific Research Center ethical committee and were performed in accordance with the recommendations and policies of the United States National Institutes of Health Principles of Laboratory Animal Care (1996 edition). Animal housing and experiments were conducted in facilities approved by the French veterinary national department (approval number: A1305519). All experiments were performed during the light phase of a 12-h day/ night cycle (lights on at 7:00 AM).

All other experimental procedures were approved by the Abbott Animal Welfare Office (Ludwigshafen, Germany) and were performed in accordance with the recommendations and policies of the United States National Institutes of Health Principles of Laboratory Animal Care (1996 edition). Animal housing and experiments were conducted in facilities with full Association for Assessment and Accreditation of Laboratory Animal Care (AAALAC) accreditation. All experiments were performed during the light phase of a 12-h day/night cycle (lights on at 5:30 AM).

\section{Results}

\section{Anti-NgR1 antibodies bind to rat and human NgR1}

Consecutive immunizations of mice with recombinant human or rat NgR1-His resulted in the generation of approximately $300 \mathrm{NgR} 1$ selective antibodies. Interestingly, most of the antibodies were not directed against the ligand binding site of Nogo66. Furthermore, only three antibodies bound to both human and rat NgR1. From the very few cross-reactive and ligand-blocking antibodies, we chose mAb50 for further characterization. For comparison we also employed the monoclonal anti-NgR1 antibody 7E11 [27] in the in vitro binding experiments.

In an ELISA test mAb50 bound to human and rat $\mathrm{NgR} 1$ proteins with comparable potencies of $36 \mathrm{pM}$ and $40 \mathrm{pM}$, respectively. Similarly, 7E11 potently bound to human and rat NgR1 (2.7 nM and 
$3 \mathrm{nM}$, respectively). A representative experiment is shown in Figure 1. mAb50 did not interact with mouse NgR1, control immunoglobulins or human NgR2 and NgR3 (data not shown). Biacore experiments were performed to measure the kinetics of mAb50 binding to $\mathrm{NgR} 1$. $\mathrm{mAb50}$ bound to human NgR1-Fc with a $\mathrm{K}_{\mathrm{D}}$ of $140 \mathrm{pM}\left(\mathrm{k}_{\mathrm{on}}=3.51^{*} 10^{5}\right.$ $\left.\mathrm{M}^{-1} \mathrm{~s}^{-1} ; \mathrm{K}_{\text {off }}=4.97^{\star} 10^{-5} \mathrm{~s}^{-1}\right)$, but did not bind to goat IgG or uncoated surface (data not shown).

Binding of mAb50 to cellular NgR1 was tested by FACS. Concentration-dependent binding to human and rat NgR1 expressed in HEK293F, HEK293 or CHO-K1 cell lines was found. Maximal binding was at $40 \mathrm{nM}$ in HEK293f cells expressing the human or rat $\mathrm{NgR} 1$ (Figures 2A, 2B). Expression of NgR1 was recently described on activated macrophages [31]. Therefore we explored NgR1 expression in cell lines of immune origin. In particular MOLT-4 (human acute lymphoblastic leukemia cell line) and U937 (human leukemic monocyte lymphoma cell line) cells were positively stained, indicating a possible role of $\mathrm{NgR} 1$ in the immune system (data not shown). To validate the use of the human NTera2 cells for neurite outgrowth studies, we evaluated NgR1 mRNA expression by quantitative PCR and protein surface expression by specific binding of mAb50 to these cells.

A

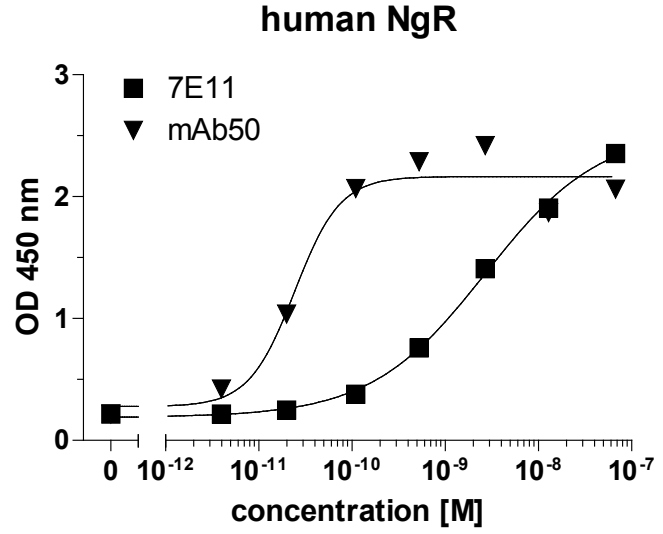

B

rat $\mathrm{NgR}$

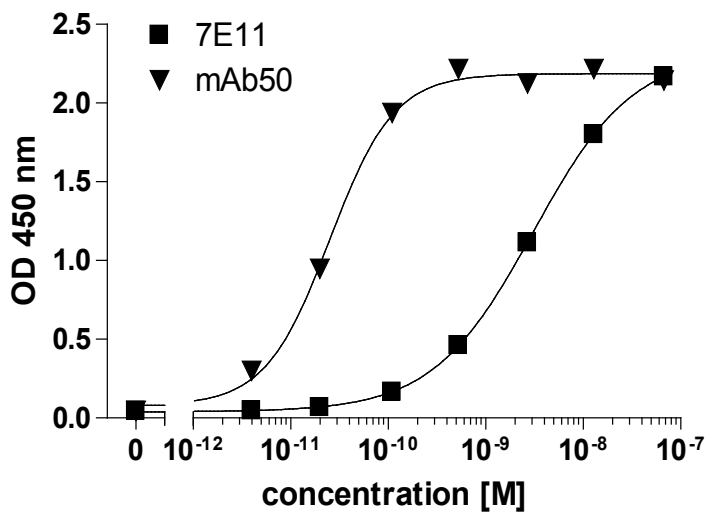

Figure 1: Anti-NgR1 antibodies bind to human and rat NgR1 with high affinity.

Plates were coated with human $\mathrm{NgR} 1$ (A) and rat $\mathrm{NgR} 1$ (B), respectively. Binding of 7E11 (squares), mAb50 (triangles) was measured at increasing concentrations of the antibody. The data from a representative experiment are shown. 5 independent experiments were done in identical fashion.

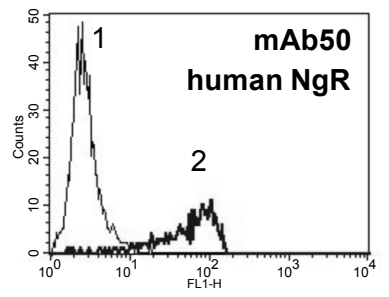

(A)

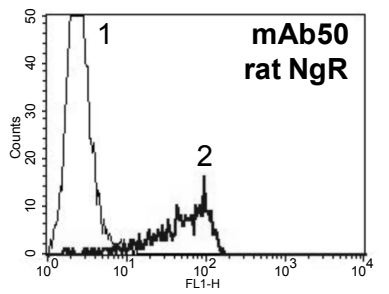

(B)

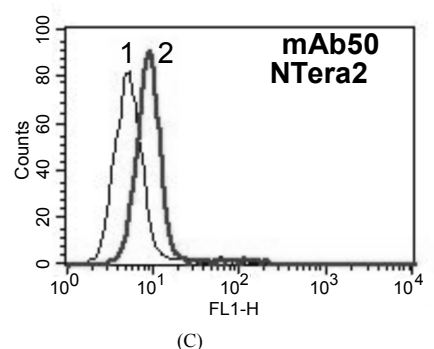

(C)

Figure 2: mAb50 binds to human and rat cellular NgR1.

Binding of mAb50 to cellular human and rat NgR1 was tested through FACS analysis on HEK293F cells expressing human (A) or rat (B) NgR1. While in untransfected HEK293F cells no binding of either antibody was seen (1), the antibody binds to cellular NgR1, yielding a rightwardly shifted histogram (2). (C) mAb50 also binds to NTera2 cells, as indicated by a rightward shift of the histogram (2), compared to an IgG control (1). All experiments were performed at least three times. Representative data are shown.

NTera2 cells express NgR1 mRNA and mAb50 detected NgR1 on the cell surface by FACS (Figure 2C).

\section{Anti-NgR1 antibodies compete for ligand binding to $\mathrm{NgR1}$}

Ideally, anti-NgR1 antibodies would block the interaction of the receptor with its ligands, thus neutralizing the receptor and blocking the intracellular inhibitory signaling. As shown, the binding of 0.15 nM Nogo66 was concentration-dependently blocked by mAb50 with a half-maximal competition of $14 \mathrm{nM}$ (Figure 3A). In contrast, up to a concentration of $100 \mathrm{nM} 7 \mathrm{E} 11$ did not compete for Nogo66 binding (Figure 3A). This corresponds to the previously described properties of this antibody [27]. Both antibodies only partially blocked OMgp binding by about $40 \%$ at the highest antibody concentrations (Figure 3B). This suggests that the antibodies interfere with the OMgp binding site, but do not completely displace the ligand from the receptor. Thus, a partial overlap between antibody binding and OMgp binding to the receptor may exist. In contrast to the antibodies, the binding of OMgp to NgR1 was completely neutralized by soluble NgR1-Fc (IC $55 \mathrm{nM}$; Figure 3B).

As shown in Figure 3C, mAb 50 did not inhibit the binding of MAG-Fc to human NgR1-Fc. Surprisingly; also 7E11 did not compete for MAG-Fc binding in our studies, which is in contrast to a previous report [27]. As expected, NgR1-Fc $\left(\mathrm{IC}_{50} 64 \mathrm{nM}\right)$ and MAG-Fc $\left(\mathrm{IC}_{50} 92\right.$ $\mathrm{nM}$ ) competed for binding of labeled MAG-Fc to human NgR1-Fc.

\section{mAb50 competes for Nogo66 binding to cellular human and rat $\mathrm{NgR1}$}

Competition of Nogo66 binding to NgR1 in cells was studied in FACS. Compared to control (Figure 4A, histogram c), and at a 20 -fold molar excess versus Nogo66, NgR1-Fc blocked Nogo66 binding to $\mathrm{NgR} 1$ on HEK293f cells between $60 \%$ and $70 \%$ (Figure 4A, histogram b). Maximal competition of Nogo66 binding to NgR1 with mAb50 was up to $90 \%$ (Figure 4 A, grey shaded area, histogram a). As shown 


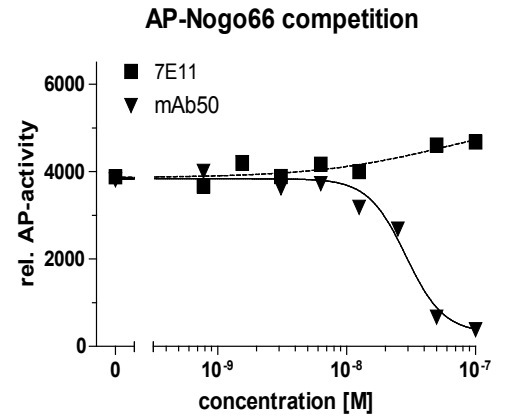

(A)

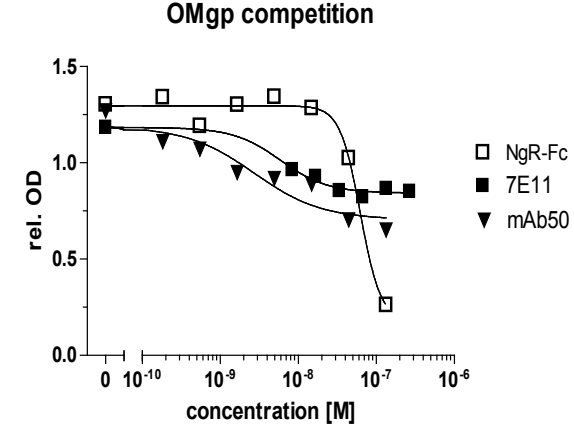

(B)

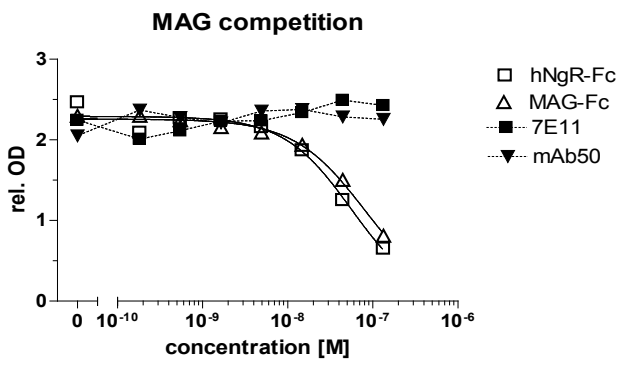

(C)

Figure 3: Anti-NgR1 antibodies differentially compete for binding of NgR1 ligands.

Competition of the binding of (A) AP-Nogo66, (B) OMgp and (C) MAG to soluble NgR1-Fc was determined. Plates were coated with soluble NgR1, incubated with the respective ligand- AP-Nogo66, MAG or OMgp- and the indicated concentration of 7E11 (squares), mAb50 (trianlges) used for competition experiments. As only partial competition of OMgp was observed by the antibodies, in (B) soluble NgR1-Fc (open sqares) was used as an additional competitor. In (C) also soluble MAG-Fc (open triangles) was employed. Data are presented from a representative experiment. Each experiment was repeated independently at least 3 times $(n=3-5)$.
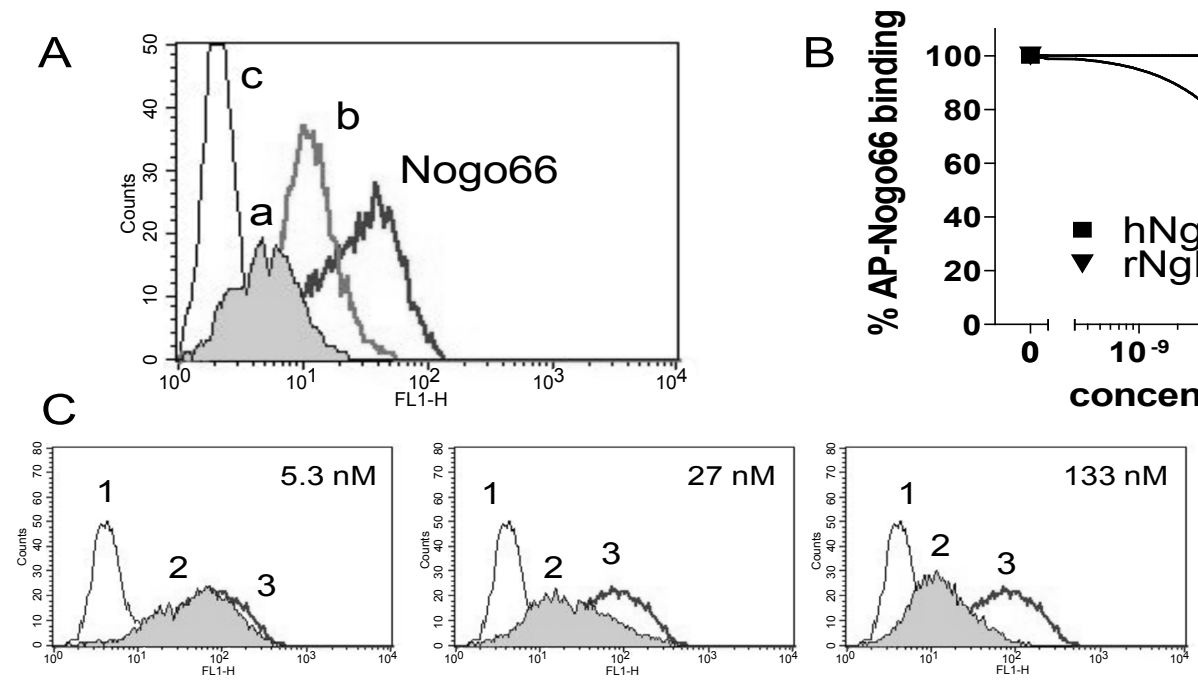

Figure 4: mAb50 competes for AP-Nogo66 binding to cellular human and rat NgR1.

Competition of AP-Nogo66 binding to cellular human or rat NgR1 (HEK293F cells) was tested by FACS analysis. (A) Representative histograms for competition of AP-Nogo66 binding to rat NgR1 for mAb50 in comparison to AP-Nogo66 competition with soluble human NgR1-Fc. a: competition of AP-Nogo66 binding with $20 \mu \mathrm{g}$ mAb50, b: competition of AP-Nogo66 binding with $20 \mu \mathrm{g}$ human NgR1-Fc, c: control, Nogo66: binding histogram of AP-Nogo66 without competitor. A monoclonal antibody of the same isotype as the anti-NgR1 antibodies (IgG2a/k) was used as a negative control. (B) Competition curves of AP-Nogo66 (1 $\mu \mathrm{g})$

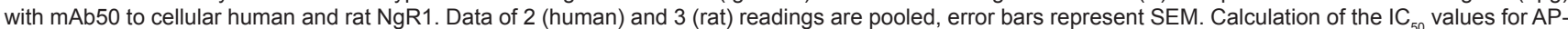
Nogo66 competition was done by Kolgomorov-Smirnov summation statistics. (C) Representative histograms with increasing amounts of mAb50, including (left to right) $5.3 \mathrm{nM}, 27 \mathrm{nM}, 133 \mathrm{nM}$ and $670 \mathrm{nM}$ of mAb50 competitor antibody. 1: control, 2: competition of $1 \mu \mathrm{g}$ AP-Nogo66 with indicated amounts of mAb50, 3 : AP-Nogo66 binding histogram without competitor. The dose-dependent leftward shift of the AP-Nogo66 signal (3) with the antibody (2) can clearly be seen. The data are representative examples; the experiment was repeated independently 3 times. 
in Figure $4 \mathrm{C}$, increasing concentrations of mAb50 resulted in a concentration-dependent competition of the ligand. A KolmogorovSmirnov test allowed the evaluation of Nogo66 competition at different concentrations of the antibody. Inhibition of Nogo66 binding to human and rat NgR1 was concentration-dependent and revealed IC50 values of $52 \mathrm{nM}$ and $11 \mathrm{nM}$ respectively (Figure 4B).

mAb50 attenuates Nogo66-induced neurite outgrowth inhibition in rat DRG neurons and human NTera2 cell aggregates

To demonstrate a neurite growth promoting effect of mAb50 in vitro, we utilized two neuronal cell types, employing Nogo66 as a neurite outgrowth inhibitory protein.

First, we employed rat primary dorsal root ganglion cells (DRGs; Figure 5). Cell cultures were either treated with buffer control (Figure 5A), with $7.3 \mathrm{nM}$ Nogo66 (Figure 5B) or with a combination of 7.3 $\mathrm{nM}$ Nogo66 and $50 \mu \mathrm{g} / \mathrm{ml} \mathrm{mAb50} \mathrm{(Figure} \mathrm{5C).} \mathrm{As} \mathrm{demonstrated}$ quantitatively in Figure 5D, without addition of Nogo66, neurite length cumulated to about $1500 \mu \mathrm{m}$ per DRG. Application of $7.3 \mathrm{nM}$ Nogo66 $(15 \mu \mathrm{g} / \mathrm{ml})$ reduced neurite length to approximately $40 \%$ of control values. mAb50 attenuated the Nogo66-induced inhibition of neurite length in a concentration-dependent fashion. This effect became statistically significant at $50 \mu \mathrm{g} / \mathrm{ml}$, which corresponds to approximately $330 \mathrm{nM}$, and neurite length reached about $60-70 \%$ of control. The antibody 7E11 did not ameliorate neurite outgrowth inhibition.

Second, we tested differentiated and aggregated human NTera2 neurons, which express human NgR1 as described above (see Figure 2C). Under control conditions (PBS) on a laminin substratum the neurons grow numerous neurites radially from the cell aggregates (Figure 6A). This outgrowth was drastically reduced when coating the plates with $100 \mathrm{nM}(15 \mu \mathrm{g} / \mathrm{ml})$ Nogo66 (Figure 6B) and could be restored partially by adding $\mathrm{mAb} 50$ (Figure $6 \mathrm{C} ; 2 \mu \mathrm{g} / \mathrm{ml}$, corresponding to approximately $13 \mathrm{nM})$. Quantification of the neurite outgrowth
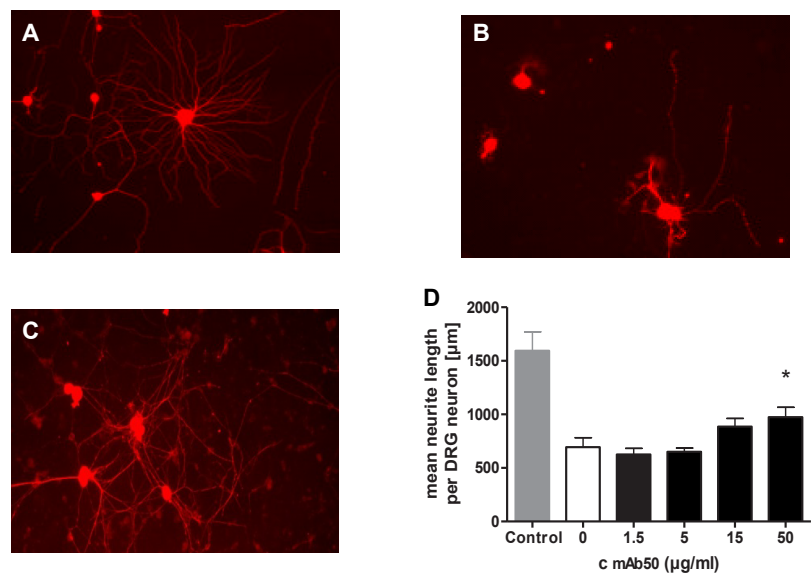

Figure 5: mAb50 attenuates AP-Nogo66-induced neurite outgrowth inhibition in rat dorsal root ganglion neurons.

mAb50 was studied in rat dorsal root ganglion (DRG) neurons. (A-C) Dissociated DRG neurons were treated with medium containing $7.3 \mathrm{nM}$ Nogo66 together with mAb50 where indicated. A: DRG culture control, B: DRG culture incubated with 7.3 nM AP-Nogo66, C: DRG culture incubated with 7.3 nM AP-Nogo66, incubated in parallel with $50 \mu \mathrm{g} / \mathrm{ml} \mathrm{mAb} 50$, D: Quantification of mAb50-induced attenuation of neurite outgrowth in rat DRG neurons. The cumulative neurite length of $>80$ cells was measured and normalized to the number of DRG neurons. Mean neurite length is given in $\mu \mathrm{m}$. Experiments were repeated 3 times. Error bars represent S.E., p-value: * $<0.05$
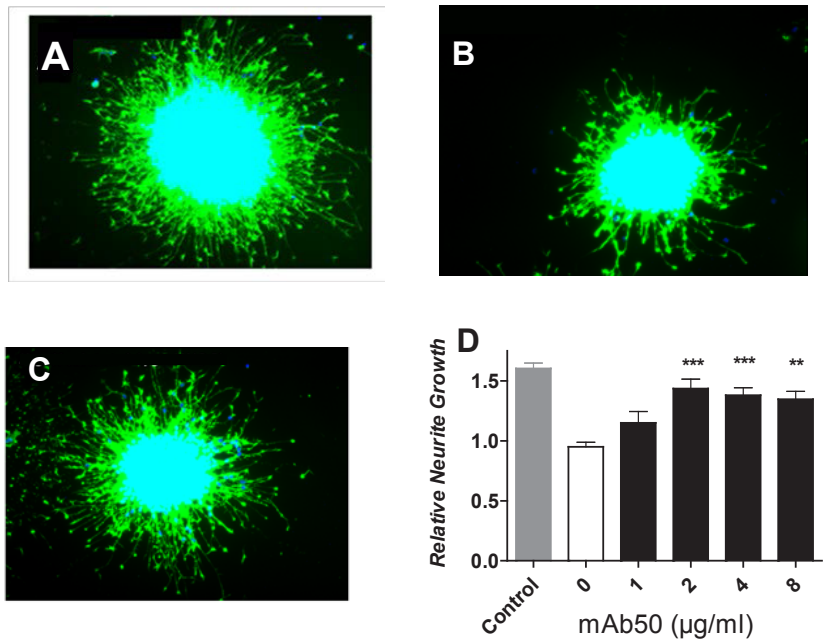

Figure 6: mAb50 attenuates AP-Nogo66-induced neurite outgrowth inhibition in differentiated human NTera2 neurons.

mAb50 was studied in differentiated human NTera2 cell aggregates. (A-C) NTera2 aggregates were placed on pre-coated plates with control substrate (1 $\mathrm{mg} / \mathrm{ml}$ laminin) or inhibitory substrate $(15 \mu \mathrm{g} / \mathrm{ml}$ AP-Nogo66 plus $1 \mathrm{mg} /$ $\mathrm{ml}$ laminin) and treated with mAb50 antibody where indicated. A: NTera2 aggregate with laminin substrate, B: NTera2 aggregate with AP-Nogo66 substrate, C: NTera2 aggregate on AP-Nogo66 substrate, incubated with $2 \mu \mathrm{g} / \mathrm{ml} \mathrm{mAb50}$, D: Quantification of mAb50- induced attenuation of neurite outgrowth in the NTera2 assay. Experiments in (A-C) were repeated at least 6 times and in $D$ mean values of 6-27 measurements are presented. Error bars represent SEM, p-value: ${ }^{* *}=0.01,{ }^{* * *}=0.001$. Scale bars in $(\mathrm{A}-\mathrm{C})$ correspond to $100 \mu \mathrm{M}$.

generated by the aggregated cells demonstrated statistically significant attenuation of neurite outgrowth inhibition, starting at $2 \mu \mathrm{g} / \mathrm{ml}$ for $\mathrm{mAb} 50$ (Figure 6D). Antibody treatment resulted in a maximal increase of neurite outgrowth of about $60-70 \%$ compared to control values (PBS). Under the same conditions, the antibody 7E11 again did not increase neurite outgrowth inhibition (data not shown). Interestingly, the potency in the DRG assay is slightly lower $(50 \mu \mathrm{g} / \mathrm{ml}, 330 \mathrm{nM})$ compared to the potency in the NTera 2 cells $(2 \mu \mathrm{g} / \mathrm{ml}, 13 \mathrm{nM})$. This difference may be due to the divergent setup of the experiments or to different sensitivities of the cells to the inhibitory effects of Nogo66.

Therefore, it can be concluded that mAb50 has the potential to stimulate neurite growth in a growth-inhibitory environment in two species, human and rat.

\section{mAb50 increases functional recovery after spinal cord injury}

To test the hypothesis that ligand-blocking anti-NgR1 antibodies are useful as a potential treatment for spinal cord injury, mAb50 was tested in a spinal cord over-hemisection model with a transection depth of around $60 \%$.

As a prerequisite for the in vivo study, we first validated the stability and bio-availability of mAb50 at high antibody concentrations. Up to a concentration of $50 \mathrm{mg} / \mathrm{ml}$, the antibody was stable in the used formulation for more than 26 days at $40^{\circ} \mathrm{C}$, as no aggregation or fragmentation of the antibody was observed (see Materials and Methods). Also the antibody kept its biological activity over the entire incubation period, as determined by binding of mAb50 to $\mathrm{NgR} 1$ in ELISA assays. Furthermore, we tested the availability of mAb50 in rats. Continuous intrathecal delivery of $5 \mathrm{mg} / \mathrm{ml} \mathrm{mAb50}$ over a time period of 14 days with an osmotic minipump yielded a concentration of 7.6 $\mu \mathrm{g} / \mathrm{ml}$ in the cerebrospinal fluid-corresponding to approximately 50 
nM. Delivery of the $25 \mathrm{mg} / \mathrm{ml}$ solution resulted in a concentration of $35 \mu \mathrm{g} / \mathrm{ml}$ (approximately $230 \mathrm{nM}$ ) in CSF. These data indicate that after intrathecal delivery, the antibody availability should suffice to mediate potential regenerative activity.

Animals were separated into three groups, a 'high antibody' group

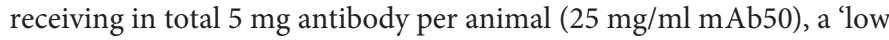
antibody' group receiving $1 \mathrm{mg}$ antibody per animal $(5 \mathrm{mg} / \mathrm{ml} \mathrm{mAb50)}$ and a 'vehicle' group (receiving excipient only). The rats underwent spinal cord over-hemisection at thoracic level 8/9, and the behavior was analyzed employing the Basso, Beattie, Bresnahan (BBB) locomotor rating scale for rats after spinal cord injury from day 1 to day 42 after surgery (Figure 7).

Apparently, animals treated with $25 \mathrm{mg} / \mathrm{ml} \mathrm{mAb} 50$ had consistently higher BBB scores throughout the observation period of 42 days. Using the mixed effects model (see Materials and Methods), we uncovered

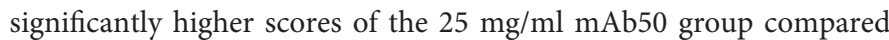
to the vehicle group $(\mathrm{p}<0.05)$ on day P21. Further, as shown in Table 1 , when the time points were combined and analyzed as described (Materials and Methods), the $25 \mathrm{mg} / \mathrm{ml} \mathrm{mAb50}$ group had significantly higher scores than the vehicle group on days P14-P42 combined $(\mathrm{p}<0.05)$.

To study the reasons for the enhanced functional recovery of the antibody-treated animals, we examined the regeneration of the corticospinal tract (CST) by visualizing nerve fibers, anteriogradely labeled with fluororuby, at and around the site of injury (Figure 8). As represented in Figure 8A, the distance between the end of the corticospinal tract and the lesion site was recorded. When analyzing the CST end distance relative to the lesion site, no statistical differences were seen between groups (Figure 8B, 1way-ANOVA). It has to be noted, however, that the variability was higher in both of the antibodytreated groups, possibly indicating a response in some of the antibodytreated animals in this measure. Next, virtual lines were defined as described (see Figure 8A) and the number of CST neurites crossing these lines was counted. The analysis of the number of axons crossing the defined lines did not show any statistical differences between groups (Figure 8C, 1way-ANOVA).

In summary, the results from the spinal cord over-hemisection

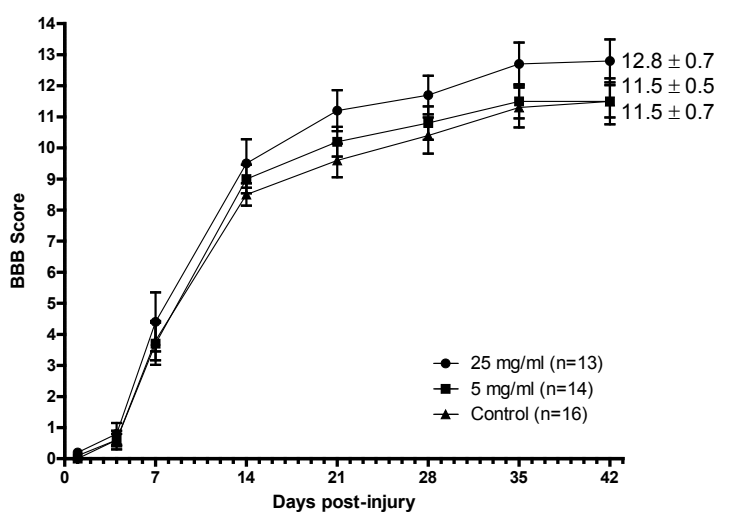

Figure 7: Improvement of locomotor scores in rats treated with mAb50 after dorsal over-hemisection.

Comparison of open field locomotor activity in rats treated with $25 \mathrm{mg} / \mathrm{ml}$ $\mathrm{mAb50}$ (circles), $5 \mathrm{mg} / \mathrm{ml} \mathrm{mAb50}$ (squares) and vehicle control (triangles) following dorsal over-hemisection. The graph illustrates the average BBB score \pm SEM for the different groups over time after the lesion. Final scores at postoperative day 42 are indicated for each group. The difference between the $25 \mathrm{mg} / \mathrm{ml} \mathrm{mAb50}$ treated group and the vehicle group $(\mathrm{p}<0.05)$ was statistically significant on day $\mathrm{P} 21$, and during the time period $\mathrm{P} 14-\mathrm{P} 42$.

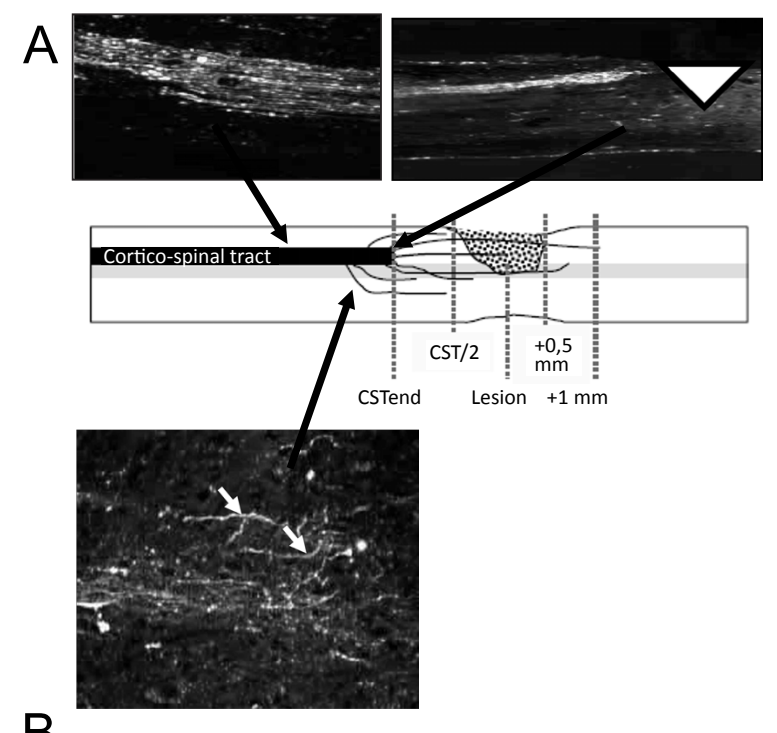

$\mathrm{B}$
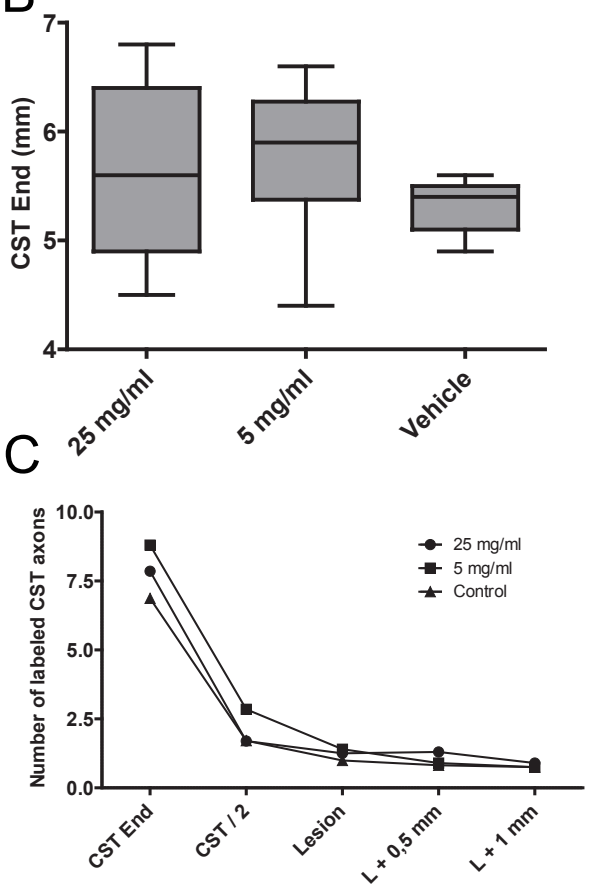

Figure 8: Assessment of corticospinal tract regeneration at the lesion site.

At the end of the behavioral studies, the animals were analyzed for regeneration of the CST. (A) At the site of injury, the location of the CST was analyzed through virtual lines, which were defined based on the distance of the CST from the site of lesion (CST end). According to this distance, CST/2 was defined as half the distance between the end of the CST and the lesion site. Also, the lesion site, lesion $+0.5 \mathrm{~mm}$ and lesion $+1 \mathrm{~mm}$ were marked. The photomicrographs exemplarily indicate the morphology of the CST (left, upper), the CST end (right, upper), also showing schematically the site of injury (white triangle), and sprouting fibers at the site of the lesion (lower micrograph). (B) The site of the CST end was analyzed in the three treatment groups. While no statistical difference exists between groups (one-way ANOVA), it can be noted that the variability in the treated animals was more pronounced. Data are presented as median, including minimum and maximum. (C) The number of axons crossing the virtual lines was used to assess the axonal outgrowth under different treatment conditions. No significant difference exists between groups (one-way ANOVA). Data are presented as mean number of axons crossing the virtual lines. 


\begin{tabular}{|l|c|c|c|c|c|c|c|c|c|}
\hline & \multicolumn{3}{|c|}{ Control } & \multicolumn{3}{c|}{ Dose $\mathbf{~ m g / m l ~}$} & \multicolumn{3}{c|}{ Dose $25 \mathrm{mg} / \mathbf{m l}$} \\
\hline Period & Mean & SE & N & Mean & SE & N & Mean & SE & N \\
\hline P1 & 0.09 & 0.05 & 16 & 0 & 0 & 14 & 0.19 & 0.07 & 13 \\
\hline P4 & 0.59 & 0.20 & 16 & 0.64 & 0.30 & 14 & 0.81 & 0.35 & 13 \\
\hline P7 & 3.78 & 0.63 & 16 & 3.68 & 0.68 & 14 & 4.38 & 0.95 & 13 \\
\hline P14 & 8.50 & 0.36 & 16 & 9.04 & 0.46 & 14 & 9.46 & 0.78 & 13 \\
\hline P21 & 9.56 & 0.54 & 16 & 10.21 & 0.48 & 14 & 11.15 & 0.66 & 13 \\
\hline P28 & 10.41 & 0.58 & 16 & 10.79 & 0.54 & 14 & 11.65 & 0.62 & 13 \\
\hline P35 & 11.31 & 0.64 & 16 & 11.50 & 0.55 & 14 & 12.69 & 0.69 & 13 \\
\hline P42 & 11.50 & 0.74 & 16 & 11.54 & 0.52 & 14 & 12.77 & 0.69 & 13 \\
\hline P1-P7 & 1.49 & 0.32 & 16 & 1.44 & 0.35 & 14 & 1.79 & 0.45 & 13 \\
\hline P14-P42 & 10.26 & 0.28 & 16 & 10.61 & 0.25 & 14 & 11.55 & 0.34 & 13 \\
\hline
\end{tabular}

Table 1: Statistical evaluation of the behavioural scores in BBB.

Treatment of rats undergoing experimental spinal cord injury showed an increased score at day $21(25 \mathrm{mg} / \mathrm{ml} \mathrm{mAb} 50$ compared to control, $\mathrm{p}<0.05)$ and the later time period of between days 14-42 was statistically different $(p<0.05)$.

model indicate that mAb50 does ameliorate recovery of function after injury. This is particularly true for the high antibody concentration of $25 \mathrm{mg} / \mathrm{ml}$. However, this overall effect cannot be easily explained by neuroanatomical improvement of the corticospinal tract. These findings suggest that already small effects in neurite outgrowth or sprouting of the CST could result in significant changes of functional recovery. Alternatively, as described previously [22], the observed functional regeneration might be carried by other fiber tracts, such as the rubrospinal or raphespinal tracts.

\section{Discussion}

In the present study we characterized anti-NgR1 antibodies ( $\mathrm{mAb50}$ and 7E11) in vitro and analyzed the potential of one anti-NgR1 antibody (mAb50) to ameliorate functional and anatomical recovery after experimental spinal cord injury in rats. $\mathrm{mAb} 50$ combines excellent in vitro properties, including high affinity to rat and human $\mathrm{NgR1}$, and ligand-blocking properties for Nogo66 and OMgp at both rat and human NgR1, with competition of Nogo66-induced neurite outgrowth inhibition in a rat and in a human (NTera2) neuronal system. These characteristics translate into increased functional recovery of rats treated with mAb50 in the spinal cord over-hemisection model.

\section{Competition of NgR1/myelin-associated inhibitor interaction}

The Nogo-66 receptor (NgR1) was the first neuronal protein for which the direct influence of its interaction with myelin-associated inhibitors (MAIs) could be shown [9]. NgR1 interacts with the three MAIs Nogo-A, MAG and OMgp [4-7,32,33]. Further insight into the relevance of the NgR1 ligands for neurite outgrowth inhibition and regeneration after spinal cord injury was gained with knockout mice for each of these ligands. While it has been described, that deletion of MAG does not increase functional recovery after injury [34], OMgp deletion results in some increased regeneration after spinal cord injury [35]. Interestingly, the authors describe increased functional recovery of OMgp (-/-) mice on a 129/Sv/C57BL/6 (129BL6) genetic background, while functional recovery of OMgp (-/-) mice on a pure C57BL/6 (BL6) genetic background did not differ from control animals. Also, four mouse strains were developed and analyzed, which do not express Nogo subtypes. Two [36,37] out of four [also 38, 39] animal models showed increased axon growth, regenerative sprouting and functional recovery after experimental SCI. Similar to the findings from Ji [35] for OMgp, apparently the background strain is important for regeneration after spinal cord injury. Here we demonstrate that mAb50 competes for Nogo66 and partially for OMgp, but not MAG binding to both human and rat NgR1. Based on the described increased potential for functional recovery after injury in the Nogo- and OMgp- knockout mice, this property of the anti-NgR1 antibodies should yield some capacity for increased regeneration after experimental SCI.

Also, our data suggest that the binding sites of Nogo66 and OMgp to NgR1 might overlap, while MAG could have a different interaction site with the receptor. These findings correspond well with described literature data, where an overlap of Nogo66 and OMgp binding to $\mathrm{NgR1}$ was shown [10], while no competition between MAG and Nogo66 could be demonstrated [40]. However, based on our studies, we cannot completely exclude overlapping interaction sites of all three ligands. Domeniconi et al. [7] demonstrated cross-competition between Nogo66 and MAG binding to NgR1 and recently a detailed study determined the binding sites of the NgR1 ligands through sitedirected mutagenesis [41]. In the latter study a partial overlap of Nogo, MAG and OMgp binding sites on the concave surface of NgR1 was demonstrated. Further experiments will be required to exactly define the epitope of $\mathrm{mAb50}$ and the exact interaction sites of the ligands with the receptor.

\section{Neutralization of neurite outgrowth inhibition in vitro}

In order to verify that the in vitro characteristics of our antibodies correspond to the required potential for increased neurite outgrowth, we decided to investigate their neutralizing properties against Nogo66induced neurite growth inhibition in primary rat DRG neurons, as well as in human NTera2-derived neurons. DRG neurons have been widely used to study neurite growth inhibition and promotion by various ligands, including Nogo66, OMgp, and MAG. Neurons differentiated from NTera2 cells are less well studied in this respect, but allow to expand studies to human postmitotic neurons. Recently, these neurons were shown to be sensitive to chondroitin sulfate proteoglycans [29], which are also known inhibitors for neurite outgrowth in primary rodent neurons. Interestingly, human NTera2 derived neurons had a 25-fold higher sensitivity for neutralization of neurite outgrowth inhibition through mAb50 compared to rat DRG neurons. One reason may be the application mode of the inhibitor: coated onto the culture dish for NTera2 neurons or dissolved in the medium for DRG neurons. A second reason could be that the inherent sensitivity of both neuronal systems for Nogo66-mediated growth inhibition might be different. The comparator antibody 7E11 did not show any neutralizing effect in either cell type, which corresponds to our finding that the antibody does not compete for Nogo66 binding to NgR1 up to a concentration of $100 \mathrm{nM}$. The antibody appears to only partially neutralize binding beyond that concentration, with a maximal effect of about $50 \%$ at 10 $\mu \mathrm{M}$ [27].

\section{Efficacy of mAb50 in a rat spinal cord injury model}

In a series of studies it was shown that blocking the interaction between NgR1 and its ligands with peptide NEP1-40 [18,19], soluble receptor constructs [20], or antibodies against the NgR1 ligand Nogo-A $[30,42,43]$ can have beneficial effects on neurite outgrowth in vitro and in vivo. To our knowledge no evidence exists to date that a direct inhibition of $\mathrm{NgR} 1$ and a direct competition of its ligands with a selective antibody could ameliorate neurite outgrowth inhibition in vivo.

In our spinal cord over-hemisection study, the BBB score is significantly different between the $25 \mathrm{mg} / \mathrm{ml}$ of mAb50 versus control when averaged across the time period from P14 to P42. In comparing single time points, we also find significantly better scores of the $25 \mathrm{mg} /$ $\mathrm{ml}$ of $\mathrm{mAb} 50$ group at P21 compared to placebo treatment.

Therefore, overall mAb50 $(25 \mathrm{mg} / \mathrm{ml})$ was able to ameliorate the 
behavioral performance of rats in the spinal cord over-hemisection model, although the response level was modest compared to the vehicle control. mAb50 has been tested for cross-reactivity with NgR2 and NgR3 and was found to be selective for the NgR1 receptor. While the neutralization of NgR1 with a ligand-blocking antibody might be a valid strategy to ameliorate functional outcome after injury, it can be speculated that a combination approach with antibodies cross-reactive with NgR2, NgR3, PirB or other inhibitory receptor types may result in better functional outcome as discussed below. It is also interesting to note that the modest functional recovery we see with our selective and highly potent anti-NgR1 antibody to some extent contrasts the sometimes larger effects with alternative approaches to neutralize the interaction of NgR1 and its ligands with peptide NEP1-40 [18,19], soluble receptor constructs [20], or antibodies against the NgR1 ligand Nogo-A $[30,42,43]$. It will be interesting to identify the reasons for this divergence. These could again be based on different receptor profiles or cross-reactivities of the different agents used to additional inhibitory factors.

\section{Relevance of NgR1 blockade for spinal tract regeneration}

Similar to our findings and in spite of high expression levels of NgR1 in the cortex, NgR1 (-/-) mice did not show increased CST regeneration $[22,23]$. In spite of this lack of CST regeneration, increased functional recovery of $\mathrm{NgR} 1(-/-)$ mice was demonstrated in two spinal cord injury models (hemisection and complete transection) [22]. Furthermore NgR1 ko mice showed increased transcranial magnetic motor-evoked potentials (tcmMEPs) six weeks after injury. While there was no difference in the regeneration of the corticospinal tract, in $\mathrm{NgR1}(-/-)$ mice increased regeneration was found in rubrospinal and raphespinal tracts. The authors argue that the increased regeneration of the rubrospinal and raphespinal tracts may contribute to the increased functional recovery they observe. It is intriguing to speculate that mAb50 treatment may also induce increased regeneration of alternative tracts beyond the CST, which may then translate into the increased functional recovery we see in mAb50 treated rats in the overhemisection model.

\section{Synergistic neutralization of neurite outgrowth inhibitory systems}

Cumulatively, our results argue that beyond functional interaction of MAIs with $\mathrm{NgR} 1$ other inhibitory systems may be important for neurite outgrowth inhibition in the severed spinal cord. These include components of myelin and their receptors [44], Ephrin A2, different members of the Semaphorin family, and the scar tissue forming after SCI, including RGM [45], and chondroitin sulfate proteogylcans (CSPGs), which all have been shown to inhibit neurite growth or to collapse growth cones. Furthermore, a human receptor has been identified through expression cloning (leukocyte immunoglobulin (Ig)-like receptor B2 (LILRB2)). Its mouse orthologue (paired immunoglobulin-like receptor B (PirB)) shares many functional properties with NgR1 [26]. This receptor interacts with the same ligands as NgR1 (Nogo66, MAG and OMgp) and partially blocks neurite outgrowth inhibition by the isolated ligands as well as myelin. Interestingly, combining neutralization of PirB with an antibody in neurons from $\mathrm{NgR} 1$ ko mice results in an almost complete attenuation of myelin-induced inhibition of neurite outgrowth in cerebellar granule neurons (CGN). Thus, simultaneous blockade of NgR1 and PirB leads to a synergistic neutralization of the inhibition of neurite outgrowth by myelin and a concomitant neutralization of both receptors could be an ideal approach to ameliorate functional recovery after SCI. These finding correspond to our results in the two neurite outgrowth assays, demonstrating only partial neutralization of Nogo66-induced neurite outgrowth inhibition after selective NgR1 blockade. In addition, NgR1 itself is not only activated through MAIs, but also was recently shown to interact with CSPGs, together with its analogue NgR3 [11]. We did not explore whether mAb50 also blocks the interaction of NgR1 with CSPGs. As the binding site of CSPGs to NgR1 is different from MAIs, $\mathrm{mAb} 50$ will probably not interfere with this inhibitory substrate.

Three NgR subtypes (NgR1, NgR2 and NgR3) have been described to date. NgR1 and NgR3 appear to interact with CSPGs [11], while $\mathrm{NgR} 1$ and NgR2 are both receptors for MAG [46]. Different inhibitory systems appear to be relevant for different types of neurons, may be expressed on different fiber systems, and may cause a vastly differential response of fibers to neutralizing treatment options [47]. This complexity makes the success for a single-targeted treatment option for SCI highly unlikely, as the inhibitory systems appear to be diverse and their function is broadly overlapping and redundant. We describe for the first time that treatment in a rat model of SCI with an NgR1selective antibody results in partial functional remission. The reference antibody 7E11 apparently has not been tested in vivo [27].

From our efforts to generate NgR1 blocking antibodies, we recently identified a group of mAbs which were cross-reactive with human, rat and in addition mouse NgR1 (data not shown). Such antibodies could open the way for a broader analysis of the potential for NgR1 neutralization also in knockout mouse models. In addition, a broader target profile for anti-NgR1 MABS would be an advantage. Interfering with the inhibitory potential of NgR1, NgR2 and NgR3 with a crossreactive antibody appears to be highly valuable [11]. If in addition such an antibody would be able to block both MAI- and CSPG-mediated inhibition, a better recovery after experimental SCI can be expected. In particular in a combination of growth-promoting and combinatorial inhibition blocking treatments, a higher response level can be reached. For example, a combination of intraocular Zymosan injection with germ-line ablation of $\mathrm{NgR} 1, \mathrm{NgR} 3$ and Rptpo resulted in a strong increase of regenerating axons in the optic nerve [11]. While mAb50 does not interact with NgR2 or NgR3, and blocks Nogo66 and OMgp, but not MAG binding to $\mathrm{NgR} 1$, it will be of high interest to next study particular combinatorial properties in our anti-NgR1 antibodies. A combination approach targeting a set of receptors mediating the inhibitory effect of MAIs and CSPG will probably have the best prospect to be effective also in human SCI patients.

\section{Relevance of NgR1 in brain physiology and further disease indications}

Beyond its suggested role in SCI, NgR1 has been discussed to be involved in neurodegenerative diseases and to possess multiple physiological functions [48-52], for example including regulation of macrophage movement in inflammatory responses [31]. With respect to its involvement in neurodegenerative diseases it was demonstrated that NgR1 directly interacts with $\mathrm{A} \beta$ and APP. Overexpression of $\mathrm{NgR}$ reduces plaque load, and also treatment of APPswe/PSEN-1 $\triangle \mathrm{E} 9$ transgenic mice with the decoy receptor $\mathrm{NgR}(310)$ ecto- $\mathrm{Fc}$ is able to reduce plaque load and leads to improved spatial memory in these animals $[48,49]$. In addition, $\mathrm{NgR} 1$ may be directly involved in plasticity and synaptic functioning $[53,54]$ and a slower acquisition of a spatial learning and memory task has recently been described for NgR1 (-/-) mice [55]. We have so far not fully explored the potential of mAb50. As 
Citation: Mezler M, Moeller A, Mueller BK, Meyer AH, Schmidt MK, et al. (2013) Blocking Nogo Receptor 1 Promotes Functional Regeneration after Spinal Cord Injury. J Neurol Disord 1: 128. doi:10.4172/2329-6895.1000128

this antibody represents a NgR1-selective, potent and ligand-blocking $\mathrm{mAb}$ it could be a valuable tool for in-depth characterization of NgR1. In combination with its proven stability for long application times it appears to be ideally suited to evaluate the relevance of this receptor in physiology and disease.

\section{Acknowledgements}

We are indebted to Karl Walter, John Harlan, Mary Leddy, Andrew Goodearl, Fabian Birkle, Marion Schanzenbaecher, and Annelise Viallat-Lieutaud for their valuable advice and outstanding technical support. Thanks to Wolfgang Fraunhofer for the antibody stability studies and the formulation of the mAb50 solution. Thanks to Alfred Hahn and Georg Terstappen for their continuous support and for critically reading the manuscript.

All authors except JCN are employees of AbbVie and may own AbbVie stocks. This study was sponsored by AbbVie. AbbVie contributed to the study design, research, and interpretation of data, writing, reviewing, and approving the publication. JCN was employed at Pharmaxon at the time. Also the studies at this institution were fully paid by AbbVie.

\section{References}

1. Schwab JM, Brechtel K, Mueller CA, Failli V, Kaps HP et al. (2006) Experimental Strategies to Promote Spinal Cord Regeneration--an Integrative Perspective. Prog Neurobiol 78: 91-116.

2. David S, Aguayo AJ (1981) Axonal Elongation into Peripheral Nervous System "Bridges" After Central Nervous System Injury in Adult Rats. Science 214: 931 933

3. Lee DH, Strittmatter SM, Sah DW (2003) Targeting the Nogo Receptor to Treat Central Nervous System Injuries. Nat Rev Drug Discov 2: 872-878.

4. Chen MS, Huber AB, van der Haar ME, Frank M, Schnell L, et al. (2000) Nogo-A Is a Myelin-Associated Neurite Outgrowth Inhibitor and an Antigen for Monoclonal Antibody IN-1. Nature 403: 434-439.

5. GrandPre T, Nakamura F, Vartanian T, Strittmatter SM (2000) Identification of the Nogo Inhibitor of Axon Regeneration As a Reticulon Protein. Nature 403: 439-444

6. Prinjha R, Moore SE, Vinson M, Blake S, Morrow R et al. (2000) Inhibitor of Neurite Outgrowth in Humans. Nature 403: 383-384.

7. Domeniconi M, Cao Z, Spencer T, Sivasankaran R, Wang K, et al. (2002) Myelin-Associated Glycoprotein Interacts With the Nogo66 Receptor to Inhibit Neurite Outgrowth. Neuron 35: 283-290.

8. Fournier AE, GrandPre T, Strittmatter SM (2001) Identification of a Receptor Mediating Nogo-66 Inhibition of Axonal Regeneration. Nature 409: 341-346.

9. Fournier AE, GrandPre T, Gould G, Wang X, Strittmatter SM (2002) Nogo and the Nogo-66 Receptor. Prog Brain Res 137: 361-369.

10. Wang X, Chun SJ, Treloar H, Vartanian T, Greer CA et al. (2002) Localization of Nogo-A and Nogo-66 Receptor Proteins at Sites of Axon-Myelin and Synaptic Contact. J Neurosci 22: 5505-5515.

11. Dickendesher TL, Baldwin KT, Mironova YA, Koriyama Y, Raiker SJ, et al (2012) NgR1 and NgR3 are receptors for chondroitin sulfate proteoglycans. Nat Neurosc 15: 703-712.

12. Nakaya N, Sultana A, Lee HS, Tomarev SI (2012) Olfactomedin 1 interacts with the nogo a receptor complex to regulate axon growth. J Biol Chem 287: 37171-37184.

13. Thomas R, Favell K, Morante-Redolat J, Pool M, Kent C, et al. (2010) LGI1 is a Nogo receptor 1 ligand that antagonizes myelin-based growth inhibition. J Neurosci 30: 6607-6612.

14. Wong ST, Henley JR, Kanning KC, Huang KH, Bothwell M et al. (2002) A P75 (NTR) and Nogo Receptor Complex Mediates Repulsive Signaling by MyelinAssociated Glycoprotein. Nat Neurosci 5: 1302-1308.

15. Mi S, Lee X, Shao Z, Thill G, Ji B, et al. (2004) LINGO-1 Is a Component of the Nogo-66 Receptor/P75 Signaling Complex. Nat Neurosci 7: 221-228.

16. Shao Z, Browning JL, Lee X, Scott ML, Shulga-Morskaya S, et al. (2005) TAJ/ TROY, an Orphan TNF Receptor Family Member, Binds Nogo-66 Receptor 1 and Regulates Axonal Regeneration. Neuron 45: 353-359.

17. Park JB, Yiu G, Kaneko S, Wang J, Chang J, et al. (2005) A TNF Receptor
Family Member, TROY, Is a Coreceptor With Nogo Receptor in Mediating the Inhibitory Activity of Myelin Inhibitors. Neuron 45: 345-351.

18. GrandPre T, Li S, Strittmatter SM (2002) Nogo-66 Receptor Antagonist Peptide Promotes Axonal Regeneration. Nature 417: 547-551.

19. Li S, Strittmatter SM (2003) Delayed Systemic Nogo-66 Receptor Antagonist Promotes Recovery From Spinal Cord Injury. J Neurosci 23: 4219-4227.

20. Li S, Liu, BP, Budel S, Li M, Ji B, et al. (2004) Blockade of Nogo-66, MyelinAssociated Glycoprotein, and Oligodendrocyte Myelin Glycoprotein by Soluble Nogo-66 Receptor Promotes Axonal Sprouting and Recovery After Spinal Injury. J Neurosci 24: 10511-10520.

21. Basso DM, Beattie MS, Bresnahan JC (1995) A Sensitive and Reliable Locomotor Rating Scale for Open Field Testing in Rats. J Neurotrauma 12 $1-21$.

22. Kim JE, Liu BP, Park JH, Strittmatter SM (2004) Nogo-66 Receptor Prevents Raphespinal and Rubrospinal Axon Regeneration and Limits Functional Recovery from Spinal Cord Injury. Neuron 44: 439-451.

23. Zheng B, Atwal J, Ho C, Case L, He XL, et al. (2005) Genetic Deletion of the Nogo Receptor Does Not Reduce Neurite Inhibition in Vitro or Promote Corticospinal Tract Regeneration in Vivo. Proc Natl Acad Sci USA 102: 12051210.

24. Chivatakarn O, Kaneko S, He Z, Tessier-Lavigne M, Giger RJ (2007) The Nogo66 Receptor NgR1 Is Required Only for the Acute Growth Cone-Collapsing but Not the Chronic Growth-Inhibitory Actions of Myelin Inhibitors. J Neurosci 27: 7117-7124.

25. Steward O, Sharp K, Yee KM, Hofstadter M (2008) A Re-Assessment of the Effects of a Nogo-66 Receptor Antagonist on Regenerative Growth of Axons and Locomotor Recovery After Spinal Cord Injury in Mice. Exp Neurol 209: 446-468.

26. Atwal JK, Pinkston-Gosse J, Syken J, Stawicki S, Wu Y, et al. (2008) PirB Is a Functional Receptor for Myelin Inhibitors of Axonal Regeneration. Science 322: $967-970$.

27. Li W, Walus L, Rabacchi SA, Jirik A, Chang E, et al. (2004) A Neutralizing Anti-Nogo66 Receptor Monoclonal Antibody Reverses Inhibition of Neurite Outgrowth by Central Nervous System Myelin. J Biol Chem 279: 43780-43788.

28. Kohler G, Milstein C (1975) Continuous Cultures of Fused Cells Secreting Antibody of Predefined Specificity. Nature 256: 495-497.

29. Lingor P, Teusch N, Schwarz K, Mueller R, Mack H, et al. (2007) Inhibition of Rho Kinase (ROCK) Increases Neurite Outgrowth on Chondroitin Sulphate Proteoglycan in Vitro and Axonal Regeneration in the Adult Optic Nerve in Vivo. J Neurochem 103: 181-189.

30. Liebscher T, Schnell L, Schnell D, Scholl J, Schneider R, et al. (2005) Nogo-A Antibody Improves Regeneration and Locomotion of Spinal Cord-Injured Rats. Ann Neurol 58: 706-719.

31. Fry EJ, Ho C, David S (2007) A Role for Nogo Receptor in Macrophage Clearance From Injured Peripheral Nerve. Neuron 53: 649-662.

32. Woolf CJ, Bloechlinger S (2002) Neuroscience. It Takes More Than Two to Nogo. Science 297: 1132-1134.

33. McGee AW, Strittmatter SM (2003) The Nogo-66 Receptor: Focusing Myelin Inhibition of Axon Regeneration. Trends Neurosci 26: 193-198.

34. Bartsch U, Bandtlow, CE, Schnell L, Bartsch S, Spillmann AA, et al. (1995) Lack of Evidence That Myelin-Associated Glycoprotein Is a Major Inhibitor of Axonal Regeneration in the CNS. Neuron 15: 1375-1381.

35. Ji B, Case LC, Liu K, Shao Z, Lee X, et al. (2008) Assessment of Functiona Recovery and Axonal Sprouting in Oligodendrocyte-Myelin Glycoprotein (OMgp) Null Mice After Spinal Cord Injury. Mol Cell Neurosci 39: 258-267.

36. Kim JE, Li S, GrandPre T, Qiu D, Strittmatter SM (2003) Axon Regeneration in Young Adult Mice Lacking Nogo-A/B. Neuron 38: 187-199.

37. Simonen M, Pedersen V, Weinmann O, Schnell L, Buss A, et al. (2003) Systemic Deletion of the Myelin-Associated Outgrowth Inhibitor Nogo-A Improves Regenerative and Plastic Responses after Spinal Cord Injury. Neuron 38: 201-211.

38. Zheng B, Ho C, Li S, Keirstead H, Steward O, et al. (2003) Lack of Enhanced Spinal Regeneration in Nogo-Deficient Mice. Neuron 38: 213-224.

39. Lee JK, Chan AF, Luu SM, Zhu Y, Ho C, et al. (2009) Reassessment of 
Citation: Mezler M, Moeller A, Mueller BK, Meyer AH, Schmidt MK, et al. (2013) Blocking Nogo Receptor 1 Promotes Functional Regeneration after Spinal Cord Injury. J Neurol Disord 1: 128. doi:10.4172/2329-6895.1000128

corticospinal tract regeneration in Nogo-deficient mice. J Neurosci 29: 86498654.

40. Liu BP, Fournier A, GrandPre T, Strittmatter SM (2002) Myelin-Associated Glycoprotein as a Functional Ligand for the Nogo-66 Receptor. Science 297: 1190-1193.

41. Lauren J, Hu F, Chin J, Liao J, Airaksinen MS, et al. (2007) Characterization of Myelin Ligand Complexes With Neuronal Nogo-66 Receptor Family Members. J Biol Chem 282: 5715-5725.

42. Huber AB, Schwab ME (2000) Nogo-A, a Potent Inhibitor of Neurite Outgrowth and Regeneration. Biol Chem 381: 407-419.

43. Freund P, Schmidlin E, Wannier T, Bloch J, Mir A, et al. (2006) Nogo-A-Specific Antibody Treatment Enhances Sprouting and Functional Recovery After Cervical Lesion in Adult Primates. Nat Med 12: 790-792.

44. Xie F, Zheng B (2008) White Matter Inhibitors in CNS Axon Regeneration Failure. Exp Neurol 209: 302-312.

45. Hata K, Fujitani M, Yasuda YM, Doya H, Saito T, et al. (2006) RGMa Inhibition Promotes Axonal Growth and Recovery After Spinal Cord Injury. J Cell Biol 173: 47-58.

46. Venkatesh K, Chivatakarn O, Lee H, Joshi PS, Kantor DB, et al. (2005) The Nogo-66 receptor homolog NgR2 is a sialic acid-dependent receptor selective for myelin-associated glycoprotein. J Neurosci 25: 808-822.

47. Giger RJ, Venkatesh K, Chivatakarn O, Raiker SJ, Robak L, et al. (2008) Mechanisms of CNS myelin inhibition: evidence for distinct and neuronal cell type specific receptor systems. Restor Neurol Neurosci 26: 97-115.
48. Park JH, Gimbel DA, GrandPre T, Lee JK, Kim JE, et al. (2006) Alzheimer Precursor Protein Interaction With the Nogo-66 Receptor Reduces AmyloidBeta Plaque Deposition. J Neurosci 26: 1386-1395.

49. Park JH, Widi, GA, Gimbel DA, Harel NY, Lee DH et al. (2006) Subcutaneous Nogo receptor removes brain amyloid-beta and improves spatial memory in Alzheimer's transgenic mice. J Neurosci 26: 13279-13286.

50. Hsu R, Woodroffe A, Lai WS, Cook MN, Mukai J, et al. (2008) Nogo Receptor 1 (RTN4R) As a Candidate Gene for Schizophrenia: Analysis Using Human and Mouse Genetic Approaches. PLOS one 2: e1234.

51. Satoh J, Onoue H, Arima K, Yamamura T (2005) Nogo-A and Nogo Receptor Expression in Demyelinating Lesions of Multiple Sclerosis. J Neuropathol Exp Neurol 64: 129-138.

52. Budel S, Padukkavidana T, Liu BP, Feng Z, Hu F, et al. (2008) Genetic Variants of Nogo-66 Receptor With Possible Association to Schizophrenia Block Myelin Inhibition of Axon Growth. J Neurosci 28: 13161-13172.

53. McGee AW, Yang Y, Fischer QS, Daw NW, Strittmatter SM (2005) ExperienceDriven Plasticity of Visual Cortex Limited by Myelin and Nogo Receptor. Science 309: 2222-2226.

54. Lee H, Raiker SJ, Venkatesh K, Geary R, Robak LA, et al. (2008) Synaptic Function for the Nogo-66 Receptor NgR1: Regulation of Dendritic Spine Morphology and Activity-Dependent Synaptic Strength. J Neurosci 28: 27532765.

55. van Gaalen MM, Relo AL, Mueller BK, Gross G, Mezler M (2012) NOGO66 receptor deficient mice show slow acquisition of spatial memory task performance. Neurosci Lett 510: 58-61.
This article was originally published in a special issue, Regeneration of Central Nervous System handled by Editor. Dr. Athanasios K.

Petridis, University of Schleswig Holstein, Germany 